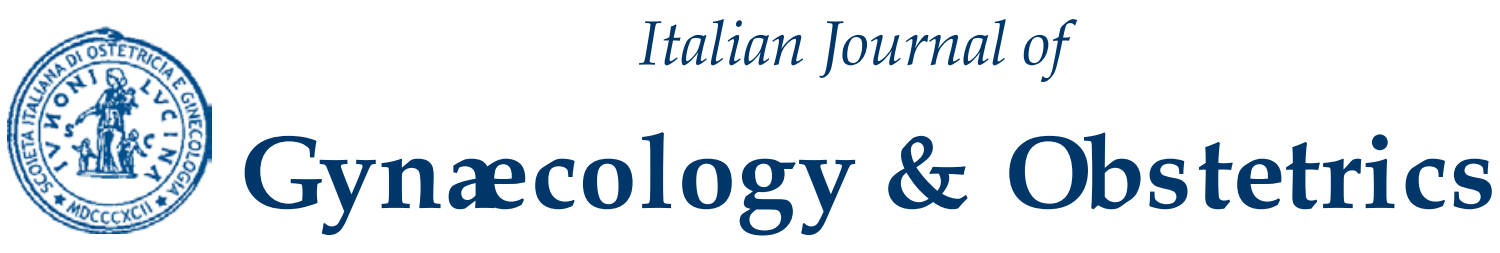

March 2020 - Vol. 32 - N. 1 - Quarterly - ISSN 2385 - 0868

\title{
Ovarian cancer surgery and BRCA test: a nationwide Italian survey
}

\author{
V. Ghizzoni ${ }^{1}$, A. Fagotti ${ }^{1,2}$, C. Marchetti², T. Pasciuto ${ }^{2}$, G. Scambia ${ }^{1,2}$, A. Pietragalla ${ }^{2}$ \\ ${ }^{1}$ Catholic University Sacred Heart Rome, Italy \\ ${ }_{2}^{2}$ Fondazione Policlinico Universitario A. Gemelli IRCCS Rome, Italy
}

\section{ABSTRACT}

Background. Ovarian cancer (OC) is the most lethal gynecological malignancy in developed countries. Beyond surgery, the backbone treatment of advanced OC is platinumbased chemotherapy. The traditional treatments can be improved by the addition of new target therapies and the breast-related cancer antigens (BRCA) genes represents a potential therapeutic target. Current guidelines recommend BRCA testing for all epithelial OC patients. The objective of the present study is to elucidate the actual scenario of the Italian OC care centers regarding surgery and BRCA testing.

Methods. We conducted a web-based cross-sectional national survey. All invited participants received an e-mail with a 21-item electronic questionnaire accessible through a direct anonymized link. No formal statistical hypothesis was predefined according to the exploratory intent of the survey.

Results. Two hundred-sixtythree potential centers were involved in the survey; 109/263 centers (41.4\%) declared advanced OC treatment expertise and are more frequently located in Northern and Central Italian regions $(p=0.0003)$. In the southern Italy, OC centers usually refer patients to other centers $(p=005)$. Most centers $(>50 \%)$ perform BRCA test in more than $60 \%$ of their OC patients but only $36.1 \%$ of centers request BRCA status on tumor tissue (sBRCA).

Conclusions. BRCA testing is not homogeneously diffused throughout Italian regions and overall sBRCA testing is not high $(36.1 \%)$. In the era of personalized medicine, sBRCA testing should be offered to all epithelial OC patients to guarantee target therapy and prevention strategies for relatives with BRCA mutation.

Key words: ovarian cancer; surgery; BRCA test; survey

\section{SOMMARIO}

Obiettivo. Il carcinoma ovarico è la prima causa di morte tra le neoplasie ginecologiche nei paesi sviluppati. Oltre alla chirurgia, il trattamento standard del carcinoma ovarico avanzato è rappresentato dalla chemioterapia a base di platino. L'aggiunta di nuove terapie target, come i farmaci che agiscono sui geni BRCA, possono migliorare l'efficacia delle terapie tradizionali. Le linee guida attuali raccomandano l'esecuzione del test BRCA per tutte le pazienti con tumore ovarico epiteliale.

L'obiettivo del presente studio è quello di chiarire l'effettivo scenario dei centri di cura del carcinoma ovarico avanzato in Italia, per quanto concerne la chirurgia e l'approccio di richiesta del test BRCA.

Metodi. Abbiamo condotto un'indagine nazionale trasversale online. Tutti i partecipanti invitati hanno ricevuto un'email con un questionario elettronico di 21 domande, accessibile tramite un collegamento diretto anonimo. Nessuna ipotesi statistica formale era predefinita in accordo con l'intento esplorativo dell'indagine.

Risultati. Duecentosessantatre centri potenziali sono stati coinvolti nell'indagine; $109 / 263$ centri $(41,4 \%)$ hanno dichiarato di trattare il tumore ovarico avanzato; questi si trovano più frequentemente nelle regioni dell'Italia settentrionale e centrale (p.0.0003). Nell'Italia meridionale, i centri di solito indirizzano i pazienti ad altri centri (p-005). La maggior parte dei centri (50\%) esegue il test BRCA in più del $60 \%$ delle pazienti con tumore ovarico, ma solo il $36,1 \%$ dei centri richiede il test BRCA sul tessuto tumorale (sBRCA). Conclusioni. Il test BRCA non è diffuso in modo omogeneo in tutte le regioni italiane e i test sBRCA complessivi non sono elevati (36,1\%). Nell'era della medicina personalizzata, il test sBRCA dovrebbe essere offerto a tutte le pazienti con tumore ovarico epiteliale per garantire strategie terapeutiche e di prevenzione per i parenti affetti da mutazione BRCA.

\section{Corresponding Author: Giovanni Scambia}




\section{INTRODUCTION}

Ovarian cancer (OC) is the most lethal gynecological malignancy in developed countries (1). It is the seventh most common cancer in women worldwide, accounting for nearly $4 \%$ of all new female cancer cases (2). According to data from AIOM and AIRTUM, nearly 5,200 new OCs were diagnosed in 2018 in Italy (3). Approximately $90 \%$ of all OC cases are epithelial (4). High grade serous ovarian cancer (HGSOC) is the most common subtype, often diagnosed in Stage III (51\%) and IV (29\%), when disease has already spread beyond the peritoneum leading to a modest 5-year-cause specific survival of $42 \%$ and $26 \%$, respectively (5). Standard front-line treatment for advanced OC has remained cytoreductive surgery with the goal of no residual disease (R0), followed by the combination of platinum and taxane chemotherapy with the addition of bevacizumab in first line treatment of "high risk" patients (6).

In case of recurrence/relapse the platinum free interval (PFI) has been used up to now to guide therapeutic choices. Nowadays the definition of PFI results outdated considering the new emerging therapies (target and not target) (7).

In the era of tailored medicine, the study of biological features and molecular pathways in OC identified other factors responsible for treatment response, overcoming the traditional dichotomy: platinum-sensitive vs platinum-resistant patients (8). In this scenario, breast related cancer antigens (BRCA) and homologous recombination deficiency (HRD) status can be considered as novel biomarkers predictive of response to standard chemotherapy (platinum agents, pegylated liposomal doxorubicin and trabectedin) as well as to poly-adenosine di- phosphate (ADP) ribose polymerase (PARPs) inhibitors (PARPis) treatment. HGSOC are characterized by ubiquitous TP53 mutations, and significant focal DNA copy number alterations (9). Approximately $15-20 \%$ of HGSOCs may be inherited, with the most common germline mutations related to alterations in BRCA1 and BRCA2 genes. In absence of a germline mutation, the somatic mutation rate reported in available literature ranges between 5\% to $7 \%$ and frequency as well as type of mutations differs among populations (10). When either BRCA1 or BRCA2 is defective, homologous recombination is dysfunctional and the reparation of Double-Strand-Break (DSBs) is performed through alternative repair mechanisms such as nonhomologous end-joining (NHEJ) and single-strand repair (SSBs) (11). SSBs repair involves a variety of mechanisms such as base excision repair (BER) and nucleotide excision repair, all of which are supported by PARPs proteins (12). PARPs constitute a family of 18 proteins involved in SSBs and BER, which are activated by DNA damage and facilitate DNA repair. PARP inhibitors prevent the repair of DNA SSBs, transforming them into DNA DSBs. When homologous recombination is not efficacious (HRD), as it is in patients with BRCA mutations, the DNA DSBs cannot be repaired and the PARP inhibition ultimately results in cell death. This mechanism, named synthetic lethality, is an important therapeutic target in HGSOC (13). Therefore, we designed a national survey across Italian centers/institutions with the aim to collect data regarding practices in OC surgery. Secondly, we defined the current scenario of BRCA testing at the time of diagnosis to improve awareness of target therapies in advanced OC patients. The survey was carried out by SIGO (Società Italiana di Ginecologia e Ostetricia).

\section{MATERIALS AND METHODS}

\section{Survey Development}

We collected data on routine clinical practice in the management of advanced OC and BRCA testing with a questionnaire-based survey, which we designed with a panel of experts including physicians, statisticians, and data managers. A subset of physicians, not directly involved in the survey development, validated the questionnaire regarding readability, usability, and clarity of questions and were asked to describe drawbacks as well as suggestions for improvements. Details about center location, type of center/institution, number and features of surgery, number of BRCA tests performed annually have been collected. The final survey contained 21 questions (Figure 1). The institutional e-mail addresses of potential participants were retrieved from the health ministry's database containing all Italian gynecologic units. The survey was emailed to national centers including 


\begin{tabular}{|l|}
\hline 1 Do you perform ovarian cancer surgery? \\
\hline 2 How many primary debulking surgery \\
(PDS)/year?
\end{tabular}

3 How many interval debulking surgery (IDS)/year?

4 Which is your optimal cytoreduction rate (Residual tumor $=0$ ) in PDS?

5 Which is your optimal cytoreduction rate (Residual tumor $=0$ ) in IDS?

6 Do you have a multidisciplinary tumor board (MTD)?

7 Which other physician are involved in MTB?

8 Which is the timing of MTB?

9 Is the intraoperative histological examination a matter of practice?

10 How many days pass between surgery and definitive histological diagnosis?

11 What is the rate of performing BRCA test in high grade serous ovarian cancer patients?

12 Do you perform somatic BRCA test?

13 If yes, which is the rate of somatic BRCA test?

14 Which is the medical specialist who requests somatic BRCA test?

15 Which physicians provide pre BRCA test counselling?

16 Do you perform pre BRCA test counselling at the same timing of surgery informed consent?

17 What is the timing required to obtain BRCA somatic test results?

18 Do you perform germline BRCA test in case of a positive somatic BRCA test?

19 If so, which is medical specialist who requests germinal BRCA test?

20 Do you offer gBRCA test to patient's family members in case of gBRCA positive results?

21 If so, which physician requests BRCA test?

Figure 1. Survey 21 items questionnaire

community hospitals and academic institutions as an online-available questionnaire. A dedicated electronic Case Report Form (eCRF) was created to collect data. Study data was accrued prospectively and managed using REDCap electronic data capture tools hosted at the
Fondazione Policlinico Universitario A. Gemelli IRCCS (https:/ / redcap-irccs.policlinicogemelli.it/). REDCap (Research Electronic Data Capture) is a secure, web-based application designed to support data capture for research studies, providing an intuitive interface for validated data entry, automated export procedures for seamless data downloads to common statistical packages and procedures to import data from external sources (14).

Only people officially registered for this survey obtained a user login to access the REDCap web platform and entered/managed data. The questionnaire structure and format allowed the direct capture of data into Redcap database amenable to be subsequently used for statistical analysis. The survey was anonymous. All participants were invited to respond the 21 items questionnaire that assessed physicians' practice about ovarian cancer surgery (10 items) and BRCA testing attitude (11 items) as reported in Figure 1. Responders did not receive any remuneration. After the first invitation, if no response was obtained after 15 days, two further reminders were sent.

\section{Statistical Analysis}

Results are presented as absolute frequency (percentage). Centers' characteristics were described referring to whole Italy and were additionally stratified for three geographical areas: North, Center and South; Italian islands were included in the last group. $X 2$ or Fisher's exact tests were used to compare characteristics of centers belonging to different geographical areas. Twosided tests were applied and the significance level was set at $p<0.05$. All statistical calculations were performed using the Stata software version 13.0 (Stata Corp, College Station, TX).

\section{RESULTS}

\section{Geographic Area, Practice Settings}

This survey was conducted from June 2018 to September 2018. Table I and Table II summarize OC surgery and BRCA testing center characteristics according to geographical areas with corresponding questions. 
Table I. Hospital characteristics according to geographical areas *

\begin{tabular}{|c|c|c|c|c|c|}
\hline Characteristic & All centers & $\begin{array}{l}\text { Northern } \\
\text { Italy }\end{array}$ & $\begin{array}{l}\text { Central } \\
\text { Italy }\end{array}$ & $\begin{array}{l}\text { Southern } \\
\text { Italy } \\
\text { and Island }\end{array}$ & $\mathbf{p}$ \\
\hline \multicolumn{6}{|l|}{ Centers involved in the survey } \\
\hline Centers partecipating to the survey & 263 & 107 & 47 & 109 & \\
\hline $\begin{array}{l}\text { Centers surgically treating advanced ovarian } \\
\text { cancer }\end{array}$ & $109 / 263(41.4)$ & $60 / 107(56.1)$ & $17 / 47(36.2)$ & $32 / 109(29.4)$ & 0.0003 \\
\hline $\begin{array}{l}\text { Centers which address patients to referral } \\
\text { centers }\end{array}$ & $133 / 138(96.4)$ & $42 / 45(93.3)$ & $27 / 29(93.1)$ & $64 / 64(100)$ & 0.05 \\
\hline \multicolumn{6}{|l|}{ Primary Debulking Surgery (PDS) } \\
\hline Nr of surgeries per year & & & & & 0.23 \\
\hline $0-20$ & $58 / 109(53.2)$ & $30 / 60(50.0)$ & $12 / 17(70.6)$ & $16 / 32(50.0)$ & \\
\hline $20-50$ & $42 / 109(38.5)$ & $27 / 60(45.0)$ & $4 / 17(23.5)$ & $11 / 32(34.4)$ & \\
\hline$>50$ & $9 / 109(8.3)$ & $3 / 60(5.0)$ & $1 / 17(5.9)$ & $5 / 32(15.6)$ & \\
\hline Percentage of optimal cytoreduction & & & & & 0.65 \\
\hline$<50 \%$ & 14/108 (13.0) & $7 / 60(11.7)$ & $1 / 17(5.9)$ & 6/31 (19.4) & \\
\hline $50-70 \%$ & $38 / 108(35.2)$ & $23 / 60(38.3)$ & $5 / 17(29.4)$ & $10 / 31(32.3)$ & \\
\hline$>70 \%$ & $56 / 108(51.9)$ & $30 / 60(50.0)$ & $11 / 17(64.7)$ & $15 / 31(48.4)$ & \\
\hline \multicolumn{6}{|l|}{ Interval Debulking Surgery (IDS) } \\
\hline \multicolumn{2}{|l|}{$\mathrm{Nr}$ of surgeries per year } & & & & 0.42 \\
\hline $0-20$ & $85 / 109$ (78.0) & $49 / 60(81.7)$ & $14 / 17(82.4)$ & $22 / 32(68.7)$ & \\
\hline $20-50$ & $20 / 109$ (18.3) & $10 / 60(16.7)$ & 2/17 (11.8) & $8 / 32(25.0)$ & \\
\hline$>50$ & $4 / 109(3.7)$ & $1 / 60(1.7)$ & $1 / 17(5.9)$ & $2 / 32(6.3)$ & \\
\hline Percentage of optimal cytoreduction & & & & & 0.24 \\
\hline$<50 \%$ & $10 / 107(9.3)$ & $8 / 59(13.6)$ & $0 / 17(0.0)$ & $2 / 31(6.4)$ & \\
\hline $50-70 \%$ & $27 / 107(25.2)$ & $11 / 59(18.6)$ & $5 / 17(29.4)$ & $11 / 31(35.5)$ & \\
\hline$>70 \%$ & $70 / 107(65.4)$ & $40 / 59(67.8)$ & $12 / 17(70.6)$ & $18 / 31(58.1)$ & \\
\hline \multicolumn{6}{|l|}{ Multidisciplinary Tumor Board (MTB) } \\
\hline Nr of certers with MTB & $94 / 109(86.2)$ & $55 / 60(91.7)$ & $15 / 17(88.2)$ & $24 / 32(75.0)$ & 0.09 \\
\hline \multicolumn{6}{|l|}{ People involved } \\
\hline Gynecol-oncologist & 94/94 (100) & $55 / 55(100)$ & $15 / 15(100)$ & $24 / 24(100)$ & - \\
\hline Oncologist & $91 / 94(96.8)$ & $54 / 55(98.2)$ & $14 / 15(93.3)$ & $23 / 24(95.8)$ & 0.37 \\
\hline Pathologist & $82 / 94(87.2)$ & $51 / 55(92.7)$ & $12 / 15(80.0)$ & $19 / 24$ (79.2) & 0.11 \\
\hline Radiotherapist & $74 / 94(78.7)$ & $46 / 55(83.6)$ & $13 / 15(86.7)$ & $15 / 24(62.5)$ & 0.10 \\
\hline Radiologist & $64 / 94(68.1)$ & $41 / 55(74.5)$ & $11 / 15(73.3)$ & $12 / 24(50.0)$ & 0.09 \\
\hline Surgeon & $52 / 94(55.3)$ & $30 / 55(54.5)$ & $11 / 15(73.3)$ & $11 / 24(45.8)$ & 0.24 \\
\hline Anesthesiologist & $16 / 94(17.0)$ & $10 / 55(18.2)$ & $2 / 15$ (13.3) & $4 / 24$ (16.7) & 1.00 \\
\hline Other & $12 / 94(12.8)$ & $8 / 55(14.5)$ & $1 / 15(6.7)$ & $3 / 24(12.5)$ & 0.83 \\
\hline \multicolumn{6}{|l|}{ Meeting frequency } \\
\hline Weekly & $43 / 90(47.8)$ & $30 / 54(55.6)$ & $5 / 15(33.3)$ & $8 / 21(38.1)$ & 0.19 \\
\hline Twice monthly & $31 / 90(34.4)$ & $16 / 54(29.6)$ & $8 / 15(53.3)$ & $7 / 21(33.3)$ & 0.23 \\
\hline Monthly & $16 / 90(17.8)$ & $8 / 54(14.8)$ & $2 / 15(13.3)$ & $6 / 21(28.6)$ & 0.33 \\
\hline \multicolumn{6}{|l|}{ Histology } \\
\hline $\begin{array}{l}\text { Routinary histological examination during } \\
\text { surgery }\end{array}$ & $86 / 108(79.6)$ & $49 / 60(81.7)$ & $13 / 17(76.5)$ & $24 / 31(77.4)$ & 0.84 \\
\hline Time from surgery to histological results & & & & & 0.002 \\
\hline$<30$ days & 99/108 (91.7) & $59 / 60(98.3)$ & $16 / 17(94.1)$ & $24 / 31(77.4)$ & \\
\hline$\geq 30$ days & 9/108 (8.3) & $1 / 60(1.7)$ & $1 / 17(5.9)$ & $7 / 31$ (22.6) & \\
\hline
\end{tabular}

Results are presented as $n(\%)$. * According to National Institute of Statistic (INSTAT) classification. 
Table II. Survey characteristics related to BRCA according to geographical areas *

\begin{tabular}{|c|c|c|c|c|c|}
\hline Characteristic & All centers & $\begin{array}{l}\text { Northern } \\
\text { Italy }\end{array}$ & $\begin{array}{l}\text { Central } \\
\text { Italy }\end{array}$ & $\begin{array}{l}\text { Southern } \\
\text { Italy } \\
\text { and Island }\end{array}$ & $\mathrm{p}$ \\
\hline \multicolumn{6}{|c|}{ Percentage of HGSOC patients tested for BRCA mutation per center } \\
\hline $0-30 \%$ & $31 / 106(29.2)$ & $16 / 58(27.6)$ & $6 / 17(35.3)$ & $9 / 31(29.0)$ & \\
\hline $31-60 \%$ & $15 / 106(14.2)$ & $7 / 58(12.1)$ & 2/17 (11.8) & 6/31 (19.4) & \\
\hline$>60 \%$ & $60 / 106(56.6)$ & $35 / 58(60.3)$ & $9 / 17(52.9)$ & $16 / 31(51.6)$ & \\
\hline \multicolumn{6}{|l|}{ sBRCA } \\
\hline Nr of centers which performed sBRCA & $39 / 108(36.1)$ & $19 / 60(31.7)$ & $7 / 17(41.2)$ & $13 / 31(41.9)$ & 0.56 \\
\hline Percentage of sBRCA performed per center & & & & & 0.57 \\
\hline $0-30 \%$ & $19 / 38(50.0)$ & $7 / 18(38.9)$ & $5 / 7(71.4)$ & $7 / 13(53.8)$ & \\
\hline $31-60 \%$ & $4 / 38(10.5)$ & $2 / 18(11.1)$ & $1 / 7(14.3)$ & $1 / 13(7.7)$ & \\
\hline$>60 \%$ & $15 / 38(39.5)$ & $9 / 18(50.0)$ & $1 / 7(14.3)$ & $5 / 13(38.5)$ & \\
\hline \multicolumn{6}{|l|}{ Specialist involved in sBRCA management } \\
\hline \multicolumn{6}{|l|}{ Test request } \\
\hline Gynecol-oncologist & $33 / 66(50.0)$ & $16 / 40(40.0)$ & $7 / 13(53.8)$ & 10/13 (76.9) & 0.07 \\
\hline Oncologist & $34 / 66(51.5)$ & $18 / 40(45.0)$ & $7 / 13(53.8)$ & $9 / 13(69.2)$ & 0.31 \\
\hline Pathologist & $4 / 66(6.1)$ & $3 / 40(7.5)$ & $0 / 13(0.0)$ & $1 / 13(7.7)$ & 0.82 \\
\hline Genetist & $11 / 66(16.7)$ & $6 / 40(15)$ & $4 / 13(30.8)$ & $1 / 13(7.7)$ & 0.09 \\
\hline \multicolumn{6}{|l|}{ Pre-test counseling } \\
\hline Gynecol-oncologist & $38 / 66(57.6)$ & $23 / 40(57.5)$ & $6 / 13(46.2)$ & $9 / 13(69.2)$ & 0.49 \\
\hline Oncologist & $32 / 66(48.5)$ & $18 / 40(45.0)$ & $7 / 13(53.8)$ & $7 / 13(53.8)$ & 0.78 \\
\hline Pathologist & $0 / 66(0.0)$ & $0 / 40(0.0)$ & $0 / 13(0.0)$ & $0 / 13(0.0)$ & - \\
\hline Genetist & $13 / 66(19.7)$ & $7 / 40(17.5)$ & $4 / 13(30.8)$ & $2 / 13(15.4)$ & 0.68 \\
\hline $\begin{array}{l}\text { Concomitant sBRCA and surgical informed } \\
\text { consent }\end{array}$ & $24 / 51(47.1)$ & $14 / 29(48.3)$ & $4 / 9(44.4)$ & $6 / 13(46.2)$ & 0.97 \\
\hline \multicolumn{6}{|l|}{ Time to obtain result } \\
\hline$<2$ months & $23 / 47(48.9)$ & $11 / 24(45.8)$ & $3 / 10(30.0)$ & $9 / 13(69.2)$ & 1.00 \\
\hline 2-3 months & $17 / 47(36.2)$ & $8 / 24(33.3)$ & $5 / 10(50.0)$ & $4 / 13(30.8)$ & 0.16 \\
\hline$>3$ months & $7 / 47(14.9)$ & $5 / 24(20.8)$ & $2 / 10(20.0)$ & $0 / 13(0)$ & 0.21 \\
\hline \multicolumn{6}{|l|}{ germline BRCA } \\
\hline $\begin{array}{l}\mathrm{Nr} \text { of gBRCA test performed in case of } \\
\text { sBRCA mutation }\end{array}$ & $39 / 47(83.0)$ & $20 / 23(87.0)$ & $9 / 12(75.0)$ & $10 / 12(83.3)$ & 0.67 \\
\hline \multicolumn{6}{|l|}{ Specialist involved in test request } \\
\hline Gynecol-oncologist & $26 / 60(43.3)$ & $16 / 39(41.0)$ & $5 / 11(45.5)$ & $5 / 10(50.0)$ & 0.87 \\
\hline Oncologist & $28 / 60(46.7)$ & $16 / 39(41.0)$ & $5 / 11(45.5)$ & $7 / 10(70.0)$ & 0.26 \\
\hline Pathologist & $3 / 60(5.0)$ & $2 / 39(5.1)$ & $0 / 11(0.0)$ & $1 / 10(10.0)$ & 0.58 \\
\hline Genetist & $17 / 60(28.3)$ & $11 / 39(28.2)$ & $4 / 11(36.4)$ & $2 / 10(20.0)$ & 0.71 \\
\hline $\begin{array}{l}\mathrm{Nr} \text { of gBRCA requested for relatives in case } \\
\text { of patient's gBRCA mutation }\end{array}$ & $54 / 59(91.5)$ & $35 / 38(92.1)$ & $11 / 12(91.7)$ & $8 / 9(88.9 .0)$ & 0.98 \\
\hline \multicolumn{6}{|l|}{$\begin{array}{l}\text { Specialist involved in test request for rela- } \\
\text { tives }\end{array}$} \\
\hline Gynecol-oncologist & $21 / 58(36.2)$ & $12 / 37(32.4)$ & $4 / 12(33.3)$ & $5 / 9(55.6)$ & 0.42 \\
\hline Oncologist & $23 / 58(39.7)$ & $12 / 37(32.4)$ & $4 / 12(33.3)$ & $7 / 9(77.8)$ & 0.39 \\
\hline Pathologist & $2 / 58(3.4)$ & $1 / 37(2.7)$ & $0 / 12(0.0)$ & $1 / 9(11.1)$ & 0.35 \\
\hline Genetist & $28 / 58(48.3)$ & $20 / 37(54.1)$ & $7 / 12(58.3)$ & $1 / 9(11.1)$ & 0.05 \\
\hline
\end{tabular}

Results are presented as $n$ (\%). HGSOC: High Grade Serous Ovarian Carcinoma. BRCA: Breast Related Cancer Antigen, sBRCA: somatic BRCA. gBRCA: germline BRCA. * According to National Institute of Statistic (INSTAT) classification 
Two hundred- sixtythree potential centers were involved in the survey, 109/263 (41.4\%) reported an advanced OC treatment expertise and compiled questionnaire; the remaining 154 centers declared no expertise in surgical OC treatment and therefore, did not answer further survey questions.

$133 / 138$ centers non treating advanced OC $(96.4 \%)$ address patients to referral centers, $5 / 138$ (3.6\%) declared they haven't a referral center, while 16/154 (10.4\%) centers didn't answer the question.

$58 / 109(53.2 \%)$ centers treat with primary debulking surgery 0-20 advanced OC patients/year, $42 / 109$ (38.5\%) centers treat 20-50 OC patients/year and only $9 / 109$ (8.3\%) treat more than 50 patients/year (third question). $51.9 \%(56 / 108)$ of centers affirmed to achieve an optimal cytoreduction in more than $70 \%$ of cases (fourth question).

According to the fifth question about number/year of interval debulking surgery (IDS), $85 / 109(78 \%)$ centers treat $0-20$ advanced OC patients/year, 20/109 (18.3\%) centers treat 20-50 OC patients/year, $4 / 109(3.7 \%)$ treat more than 50 patients/year.

In this clinical setting, $65.4 \%(70 / 107)$ of centers declare to perform an optimal cytoreduction in more than $70 \%$ of cases (sixth question).

94/109 (86.2\%) centers have a multidisciplinary tumor board (MTB): gynecology-oncologist, oncologist and pathologist are the most frequent involved physicians. In most cases (47.8\%) the MTB meeting frequency is weekly, in $34.4 \%$ twice monthly in $17.8 \%$ monthly. Four centers declare to have MTB only on request. Almost all centers $(99 / 108,91.7 \%)$ perform histological examination in less than 30 days from surgery and $86 / 108(79.6 \%)$ routinely use an intraoperative frozen section evaluation.

The remaining 11 items deal with physicians' attitude of BRCA testing in OC patients.

About the half of the centers perform a BRCA test in more than $60 \%$ of their HGSOC patients but only $36.1 \%$ of centers request sBRCA. Usually, sBRCA testing is requested by gynecologyoncologists who performed correspondingly pre-test counselling. Less than half of the centers obtain sBRCA consent at the same time of surgical informed consent. The time needed to obtain BRCA test results takes from 2 to more than 3 months in about $50 \%$ of centers. In case of
sBRCA mutation, 83\% (39/47) of centers perform gBRCA (on blood sample) to verify the constitutional nature of mutation. More than $90 \%$ of centers involved in this survey, request BRCA testing for relatives in case of patients' gBRCA mutation. Genetists $(48.3 \%)$ or oncologist $(39.7 \%)$ usually are involved in gBRCA test requests for patients' relatives.

Regarding centers geographical distribution, $60 / 107(56.1 \%)$ of centers are located in Northern Italy, $17 / 47(36.2 \%)$ are located in the center of Italy and the remaining 32/109 (29.4\%) were distributed across South of Italy and the Islands, as summarized in Table I. Centers more specialized in advanced OC surgery are likely located in North and Central Italy $(p=0.0003)$. All centers in South Italy usually address patients to other referral centers $(\mathrm{p}=0.05)$.

No other statistically significant associations were found in this survey.

\section{DISCUSSION}

To the best of our knowledge, this is the first national survey about common practices and beliefs regarding BRCA testing among Italian physicians trained in OC care.

Inhomogeneity of referral centers' geographical distribution corresponds to organizational heterogeneity of regional health systems. Yet, the Southern OC centers, usually address patients in Northern and Central referral centers $(p=0.05)$. The standard OC surgery (removal of the adnexa, uterus, omentum, and pelvic and para-aortic lymph nodes) is often associated with complex surgical techniques used to debulk advanced disease like bowel resection, splenectomy, partial liver resection, peritoneal or diaphragmatic stripping. In this regards, high-volume hospitals report statistical significant survival benefits (15). Different factors are associated with improved survival for OC patients. In particular, centralized primary care and complete cytoreduction rate at primary surgery are two of the strongest predictors to survival $(16,17)$.

Moreover, complete cytoreduction rate is improved by centralization together with shortened time interval from surgery to chemotherapy, which may impact survival outcome. OC surgery centralization and a larger proportion of 
patients achieving an optimal cytoreductive surgery emphasize the importance of experienced and skilled surgeons.

Regarding MTB, more than $80 \%$ of the centers declared to meet at least twice a month. A recent systematic literature review (which included 27 articles) reported that MTBs have impact on management decisions of cancer patients. In fact, between $4 \%$ and $45 \%$ of OC cases discussed in MTBs experienced changes in diagnostic reports. Additionally, patients discussed at MTBs were more likely to receive more accurate preoperative staging and neoadjuvant/adjuvant therapy (18). The review showed limited evidence of survival outcomes, in contrast to earlier large cohort studies (19).

Regarding OC molecular characterization, sBRCA testing is uncommonly prescribed by Italian physicians; in fact only $36.1 \%$ of centers request sBRCA. In 2019, implementation of BRCA testing in OC patients and their relatives was updated (20). The sBRCA test can identify variants acquired as somatic mutations in addition to constitutional defects. Hence, in the event of a positive result, the BRCA variant must be verified with peripheral blood to verify its constitutional origin. The somatic analysis enables physicians to identify a fraction of around $7 \%$ of OC patients with a pathogenic BRCA variant that would remain unknown if test would be restricted to peripheral blood analysis (21). The complexity of the BRCA test in terms of interpretation require laboratories with high expertise to ensure high quality data. In the United States, BRCA testing has become universal for all OC patients over the last few years. It has been estimated that medical and surgical risk reduction strategies, applied to BRCA positive healthy family members, could decrease the ovarian cancer incidence by $40 \%$ within 10 years (22). Taking into account that effective OC prevention and/or screening methods are not available, it is extremely important to offer BRCA test to HGSOC. The importance of BRCA test at diagnosis, preferably on tissue, is underlined by the availability of target therapy as Parp-inhibitors. In the first-line Solo 1 trial in advanced OC, Olaparib significantly improved progressionfree survival in BRCA mutated patients; the risk of disease progression or death was $70 \%$ lower with Olaparib than with placebo (23). This landmark trial has changed practice for BRCA mutated (somatic or germline) OC patients.

Even though the present investigation is innovative and analyzes such an intriguing and interesting aspect of OC diagnostics and treatments, our study had several limitations. Firstly, this survey, might be subject to selection bias that could arise from the recruitment of a specific group of physicians that responded in a specific way to our questions. Nevertheless, we consider the physician sample as representative for the OC Italian Leads of the major Gynecologic Units (Unità Operative Complesse). This list was available from Italian Ministry of Health. Moreover, this survey was conducted from June 2018 to September 2018, before publication of SOLO1 trial results. The impressive SOLO1 results could modify physician attitude to request BRCA testing due to remarkable results of the trial. Finally, according to the exploratory intent of the survey, we did not predefine any formal statistical hypothesis and the purpose of the survey was to explore this topic more thoroughly to develop some specific hypothesis or predictions that can be tested in future research.

In our experience, Italian physicians involved in OC patient surgery do not prescribe sBRCA test as routine of patient journey. This survey is the starting point to capture the current OC patient access to BRCA molecular testing. This survey can be useful to collaborate with both institutions and patient associations to implement the OC molecular diagnostic pathway across Italian regions. In particular, referral centers should set up biobanks and national bioinformatics database to share patient's data in order to implement molecular diagnostics to ensure target therapies. Furthermore, the Italian Centers could collaborate to develop uniform molecular diagnostic test method and result reports.

Standardizing BRCA testing at diagnosis, as per international guidelines suggestion, could ensure that patients are correctly treated. sBRCA testing should be offered to all epithelial OC patient to enhance the availability of target therapy (Parp-I) and to improve, in case of a BRCA constitutional variant, relatives' prevention strategies.

\section{FUNDINGS}

AstraZeneca grant. 


\section{ACKNOWLEDGMENTS}

We thank all the anonymous participants of this survey.

\section{CONFLICTS OF INTERESTS}

AP worked in the Astrazeneca Medical Department until December 2018. 


\section{REFERENCES}

(1) Noone AM, Howlader N, Krapcho M, Miller D, Brest A, Yu M et al. SEER Cancer Statistics Review, 1975-2015. National Cancer Institute: Bethesda, MD, USA, 2015.

(2) Ferlay J, Soerjomataram I, Dikshit R, Eser S, Mathers C, Rebelo M, et al. Cancer incidence and mortality worldwide: Sources, methods and major patterns in GLOBOCAN 2012. Int J Cancer. 2015 Mar 1;136(5):E359-86.

(3) https://www.aiom.it/wp-content/uploads/2018/10/2018_NumeriCancro-operatori.pdf

(4) Ramalingam P. Morphologic, Immunophenotypic, and Molecular Features of Epithelial Ovarian Cancer. Oncology (Williston Park). 2016 Feb;30(2):166-76.

(5) Torre LA, Trabert B, DeSantis CE, Miller KD, Samimi G, Runowicz CD, et al. Ovarian cancer statistics, 2018. CA Cancer J Clin. 2018 Jul;68(4):284-296. doi: 10.3322/caac. 21456.

(6) Oza AM, Cook AD, Pfisterer J, Embleton A, Ledermann JA, Pujade-Lauraine E, et al. Standard chemotherapy with or without bevacizumab for women with newly diagnosed ovarian cancer (ICON7): overall survival results of a phase 3 randomised trial. Lancet Oncol. 2015 Aug;16 (8):928-36.

(7) Wilson MK, Pujade-Lauraine E, Aoki D, Mirza MR, Lorusso D, Oza AM et al. Fifth Ovarian Cancer Consensus Conference of the Gynecologic Cancer InterGroup: recurrent disease. Ann Oncol. 2017 Apr 1;28(4):727-732. doi: 10.1093/annonc/mdw663.

(8) Madariaga A, Lheureux S, Oza AM. Tailoring Ovarian Cancer Treatment: Implications of BRCA1/2 Mutations. Cancers (Basel). 2019 Mar 23;11(3). pii: E416.

doi: $10.3390 /$ cancers 11030416 .

(9) Ganguly B, Dolfi SC, Rodriguez-Rodriguez L, Ganesan S, Hirshfield KM. Role of biomarkers in the development of PARP inhibitors. Biomark Cancer. 2016 Mar 9;8(Suppl 1):15-25. doi: 10.4137/BIC.S36679.

(10) Ledermann J, Harter P, Gourley C, Friedlander M, Vergote I, Rustin G et al. Olaparib maintenance therapy in patients with platinumsensitive relapsed serous ovarian cancer: a preplanned retrospective analysis of outcomes by BRCA status in a randomised phase 2 trial. Lancet Oncol. 2014 Jul;15(8):852-61. doi: 10.1016/S1470-2045(14)70228-1. Epub 2014 May 31. Erratum in: Lancet Oncol. 2015 Apr;16(4):e158.

(11) Prakash R, Zhang Y,Feng W, Jasin M. Homologous recombination and human health: the roles of BRCA1, BRCA2, and associated proteins. Cold Spring Harb Perspect Biol. 2015 Apr 1;7(4):a016600.

doi: 10.1101/cshperspect.a016600.

(12) Murai J, Huang SY, Das BB, Renaud A, Zhang $\mathrm{Y}$, Doroshow JH, et al. Trapping of PARP1 and PARP2 by clinical PARP inhibitors. Cancer Res. 2012 Nov 1;72(21):5588-99. doi: 10.1158/0008-5472.CAN-12-2753.

(13) Lorusso D, Tripodi E, Maltese G, Lepori S, Sabatucci I, Bogani G, et al. Spotlight on olaparib in the treatment of BRCA-mutated ovarian cancer: design, development and place in therapy. Drug Des Devel Ther. 2018 May 29;12:1501-1509. doi: 10.2147/DDDT.S124447.

(14) Harris PA, Taylor R, Thielke R, Payne J, Gonzalez N, Conde JG. Research electronic data capture (REDCap) - A metadata-driven methodology and workflow process for providing translational research informatics support. J Biomed Inform. 2009 Apr;42(2):377-81.

doi: 10.1016/j.jbi.2008.08.010.

(15) Bristow RE, Palis BE, Chi DS, Cliby WA. The National Cancer Database report on advancedstage epithelial ovarian cancer: impact of hospital surgical case volume on overall survival and surgical treatment paradigm. Gynecol Oncol. 2010 Sep;118(3):262-7.

doi: 10.1016/j.ygyno.2010.05.025.

(16) Chang SJ, Hodeib M, Chang J, Bristow RE. Survival impact of complete cytoreduction to no gross residual disease for advanced-stage ovarian cancer: a meta-analysis. Gynecol Oncol. 2013 Sep;130(3):493-8.

doi: 10.1016/j.ygyno.2013.05.040.

(17) du Bois A, Reuss A, Pujade-Lauraine E, Harter P, Ray-Coquard I, Pfisterer J. Role of surgical outcome as prognostic factor in advanced epithelial ovarian cancer: a combined exploratory analysis of 3 prospectively randomized phase 3multicenter trials: by the Arbeitsgemeinschaft Gynaekologische Onkologie Studiengruppe Ovarialkarzinom (AGO-OVAR) and the Groupe d'Investigateurs Nationaux Pour les Etudes des Cancers de l'Ovaire (GINECO). Cancer. 2009 Mar 15;115(6):1234-44. doi: 10.1002/cncr.24149. (18) Pillay B, Wootten AC, Crowe H, Corcoran 
$\mathrm{N}$, Tran B, Bowden $\mathrm{P}$, et al. The impact of multidisciplinary team meetings on patient assessment, management and outcomes in oncology settings: A systematic review of the literature. Cancer Treat Rev. 2016 Jan;42:56-72.

(19) Kesson EM, Allardice GM, George WD, Burns HJ, Morrison DS. Effects of multidisciplinary team working on breast cancer survival: Retrospective, comparative, interventional cohort study of 13722 women. BMJ. 2012 Apr 26;344:e2718. doi: 10.1136/bmj.e2718.

(20) Gori S, Barberis M, Bella MA, Buttitta F, Capoluongo E, Carrera P, et al. Recommendations for the implementation of BRCA testing in ovarian cancer patients and their relatives. Crit Rev Oncol Hematol. 2019 Aug;140:67-72.
(21) Ellison G, Ahdesmäki M, Luke S, Waring PM, Wallace A, Wright R, et al. An evaluation of the challenges to developing tumor BRCA1 and BRCA2 testing methodologies for clinical practice. Hum Mutat. 2018 Mar;39(3):394-405. doi: 10.1002/humu.23375.

(22) Bayraktar S., Arun B. BRCA mutation genetic testing implications in the United States. Breast. 2017 Feb;31:224-232.

doi: 10.1016/j.breast.2016.11.021.

(23) Moore K, Colombo N, Scambia G, Kim BG, Oaknin A, Friedlander $M$, et al. Maintenance Olaparib in Patients with Newly Diagnosed Advanced Ovarian Cancer. N Engl J Med. 2018 Dec 27;379(26):2495-2505.

doi: 10.1056/NEJMoa1810858. 